\title{
A convenient estimation of the sources of sweet potato weevils, Cylas formicarius (Fabricius) (Coleoptera: Brentidae), in recently invaded areas in Japan, by random amplified polymorphic DNA technique
}

\author{
Kiyohisa Kawamura, ${ }^{1, \dagger}$ Tuyosi Sugimoto, ${ }^{1, *}$ Yoshinori Matsuda $^{2}$ and Hideyoshi Toyoda ${ }^{2}$ \\ ${ }^{1}$ Laboratory of Ecological Entomology, Faculty of Agriculture, Kinki University; Nara 631-8505, Japan \\ ${ }^{2}$ Laboratory of Plant Pathology and Biotechnology, Faculty of Agriculture, Kinki University; Nara 631-8505, Japan \\ (Received 15 June 2006; Accepted 26 December 2006)
}

\begin{abstract}
RAPD-PCR was used to clarify the genetic properties of the sweet potato weevil, Cylas formicarius, which was collected from several of the Southwest Islands, Ogasawara Islands, Muroto City and Yakushima Island in Japan. PCR amplification of $C$. formicarius DNA using three primer sets, i.e., T13/T13, T05/T05, and T01/T07, resulted in products of several different sizes among individuals and primer sets. The 393 wild weevils tested were classified into 27 distinctive categories by combining the three patterns detected for each weevil. The frequency of these categories varied both among islands and among collection sites within the same island. The categories confirmed for weevils from Muroto City and Yakushima Island were detected only in those from Okinawa-Hontou Island and the more northern islands of the Southwest Islands. C. formicarius from these islands probably invaded Muroto City in 1995 and Yakushima Island in 1997.
\end{abstract}

Key words: Cylas formicarius; DNA polymorphism; invasion; RAPD-PCR

\section{INTRODUCTION}

The sweet potato weevil, Cylas formicarius (Fabricius) (Coleoptera: Brentidae), is a serious pest of sweet potatoes in tropical and subtropical areas (International Institute of Entomology, 1993). It has poor dispersal ability (Sugimoto et al., 1994; Miyatake et al., 1997; Moriya and Hiroyoshi, 1998) and is spread around the world mainly by the transportation of infested tubers (Wolfe, 1991). In Japan, this weevil was first recorded on Okinawa Island in 1903 (Nawa, 1903) and is currently distributed throughout the Southwest Islands and the Ogasawara Islands. Recently, it has been found in other areas such as Muroto City and Yakushima Island, despite plant quarantine regulations; however, it has been thoroughly eradicated from these areas by emergent control projects directed by the national and prefectural governments (Fujimoto et al., 2000; Nishioka et al., 2000; Oogaki and Yokoyama, 2002). To facilitate these projects, a convenient and accurate method of estimating the sources of $C$. formicarius in newly invaded areas is desired.

The random amplified polymorphic DNA polymerase chain reaction (RAPD-PCR) has been used to analyze genetic variation in insect populations and identify insect species and biotypes (Kambhampati et al., 1992; Gawel and Bartlett, 1993; Wilkerson et al., 1993; Williams et al., 1994; Cognato et al., 1995; Moya et al., 2001; Callejas et al., 2005) because it can detect extensive genomic DNA polymorphisms (Williams et al., 1990). However, RAPD-PCR has some problems as a detection technique. It requires the standardization of PCR conditions for reliable and consistent use (Black, 1993; Unruh and Woolley, 1999; Caterino et al., 2000) because the reproducibility of amplified DNA fragments is susceptible to slight changes in the PCR conditions. Another problem is that the homology of amplified DNA fragments cannot be assumed between species (Black, 1993;

\footnotetext{
* To whom correspondence should be addressed at: E-mail: ttsugimoto@kcc.zaq.ne.jp

${ }^{\dagger}$ Present address: Okinawa Prefectural Plant Protection Center, Naha, Okinawa 902-0072, Japan DOI: $10.1303 / \mathrm{aez} .2007 .297$
} 
Unruh and Woolley, 1999). Although RAPD-PCR is not recommended for phylogenetic studies based on genetic distance, it is a fast and inexpensive method for the identification of insect species (Black, 1993).

Kawamura et al. (2002) detected genomic DNA polymorphisms in laboratory-reared $C$. formicarius using RAPD-PCR, established a reproducible protocol, and proposed a convenient procedure for classifying the genetic variation of $C$. formicarius more minutely by combining RAPD patterns from three primer sets. We used this procedure to examine the genetic variation of $C$. formicarius collected from various areas of Japan, and then estimated the sources of C. formicarius that invaded Muroto City, Kochi Prefecture, in 1995 and Yakushima Island, Kagoshima Prefecture, in 1997 (Hiramatsu, 1996; Maehara, 1998).

\section{MATERIALS AND METHODS}

Insects. Adult males $C$. formicarius were collected for one night using pheromone traps (Jansson et al., 1991) in the Southwest Islands, the Ogasawara Islands, and Muroto City, Kochi Prefecture (Fig. 1 and Table 1). Only living weevils were placed in $99.5 \%$ ethanol for preservation after collection and stored at $-20^{\circ} \mathrm{C}$ until DNA extraction.

DNA extraction and PCR amplification. DNA was extracted from the whole body of each individual using a method reported previously (Kawamura et al., 2002) and dissolved in $200 \mu \mathrm{l}$ of TE buffer. After the DNA concentration was estimated using a spectrophotometer (DU 640, Beckman, CA, USA), the solution was diluted to $10 \mathrm{ng} / \mu 1$ and stored at $4{ }^{\circ} \mathrm{C}$. The sample used for PCR was frozen at $-20^{\circ} \mathrm{C}$. We used three primer sets, i.e., T13/T13, T05/T05, and T01/T07 (Operon Technologies, CA, USA), which amplify DNA from $C$. formicarius reproducibly and provide RAPD patterns (Kawamura et al., 2002). PCR amplification was carried out under the same conditions described in Kawamura et al. (2002), and $10 \mu 1$ of the PCR products was electrophoresed in $1.5 \%$ agarose gel in TAE buffer. The gel was stained with $10 \mu \mathrm{g} / \mathrm{ml}$ ethidium bromide solution for $10 \mathrm{~min}$, visualized on a UV transilluminator at a wavelength of $312 \mathrm{~nm}$ (FV1-20M, Funakoshi, Tokyo, Japan), and imaged with a Kodak DC120 Zoom digital camera using the Electrophoresis Documentation

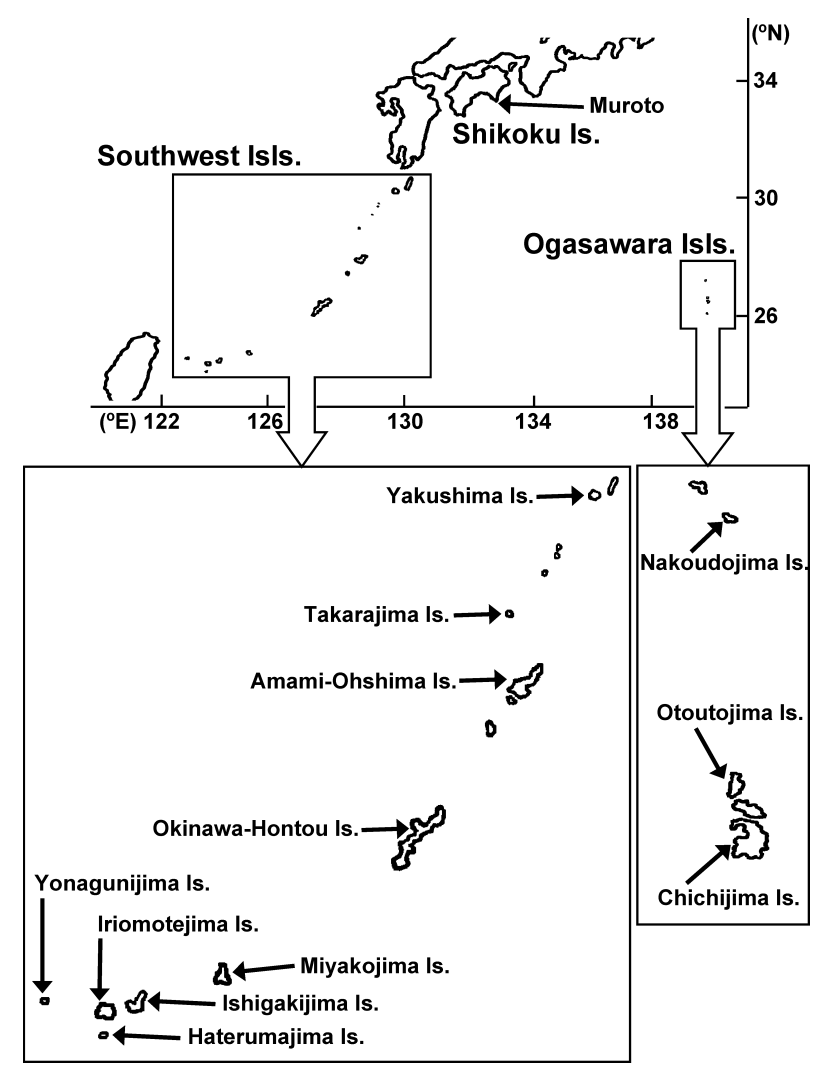

Fig. 1. Islands where C. formicarius specimens were collected in this study.

and Analysis System 120, Limited Edition (Kodak Digital Science, NY, USA), according to the manufacturer's instructions. PCR with each primer set was repeated at least three times for each specimen to assess the reproducibility of the amplified DNA fragments.

Categorization of RAPD patterns. Based upon reproducible DNA fragments, the RAPD patterns of wild $C$. formicarius amplified using the three primer sets T13/T13, T05/T05, and T01/T07 are referred to as types A, B, and C RAPD patterns, respectively. Because there were multiple RAPD patterns for each type, each individual was given a triplet notation by combining the RAPD patterns of the three types detected for that individual, following the method of Kawamura et al. (2002).

\section{RESULTS AND DISCUSSION}

The RAPD patterns of the 393 weevils examined were classified into patterns $A_{1}$ to $A_{5}, B_{1}$ to $B_{5}$, and $\mathrm{C}_{1}$ to $\mathrm{C}_{8}$ (Fig. 2). However, because some DNA fragments amplified by T01/T07 (approximately 
Table 1. Collection records of C. formicarius specimens used in this study

\begin{tabular}{|c|c|c|c|}
\hline Collection sites (No. of sites) & Collection years & Collectors and Providers & Note \\
\hline \multicolumn{4}{|l|}{ Shikoku Island } \\
\hline Muroto City, Kochi Prefecture (1) & 1995 & M. Takai and I. Yamashita & \\
\hline Muroto City, Kochi Prefecture (1) & 2000 & M. Takai and I. Yamashita & $\begin{array}{l}\text { Invaded but eradicated } \\
\text { areas of } C \text {. formicarius }\end{array}$ \\
\hline \multicolumn{4}{|l|}{ Southwest Islands } \\
\hline Yakushima Island, Kagoshima Prefecture (1) & 1997 & S. Kawasaki & \\
\hline Takarajima Island, Kagoshima Prefecture (1) & 2003 & H. Kamiwada & \\
\hline $\begin{array}{l}\text { Amami-Ohshima Island, Kagoshima } \\
\text { Prefecture }(4)^{\mathrm{a}}\end{array}$ & $2001-2003$ & S. Hayashikawa and K. Kawamura & \\
\hline Okinawa-Hontou Island, Okinawa Prefecture $(4)^{b}$ & b $\quad 2002-2004$ & H. Saragai and K. Kawamura & \\
\hline Miyakojima Island, Okinawa Prefecture (4) ${ }^{\mathrm{c}}$ & $2002-2003$ & K. Kawamura & \\
\hline Ishigakijima Island, Okinawa Prefecture (4) ${ }^{\mathrm{d}}$ & $2002-2003$ & K. Kawamura & \\
\hline Iriomotejima Island, Okinawa Prefecture $(3)^{\mathrm{e}}$ & 2003 & K. Kawamura & Infested areas of \\
\hline Haterumajima Island, Okinawa Prefecture (1) & 2003 & K. Kawamura & C. formicarius \\
\hline Yonagunijima Island, Okinawa Prefecture (1) & 2003 & H. Saragai & \\
\hline \multicolumn{4}{|l|}{ Ogasawara Islands } \\
\hline Chichijima Island, Tokyo Metropolis (1) & 2004 & S. Sato & \\
\hline Otoutojima Island, Tokyo Metropolis (1) & 2004 & S. Sato & \\
\hline Nakoudojima Island, Tokyo Metropolis (1) & 2004 & S. Sato & \\
\hline
\end{tabular}

${ }^{\text {a }}$ Collected from Tatsugou Town, Yamato Village, Sumiyou Village and Setouchi Town in Amami-Ohshima Island.

${ }^{\mathrm{b}}$ Collected from Nakijin Village, Nago City, Yomitan Village and Itoman City in Okinawa-Hontou Island.

${ }^{\mathrm{c}}$ Collected from four sites of Miyakojima City in Miyakojima Island.

${ }^{\mathrm{d}}$ Collected from four sites of Ishigaki City in Ishigakijima Island.

${ }^{\mathrm{e}}$ Collected from three sites of Taketomi Town in Iriomotejima Island.

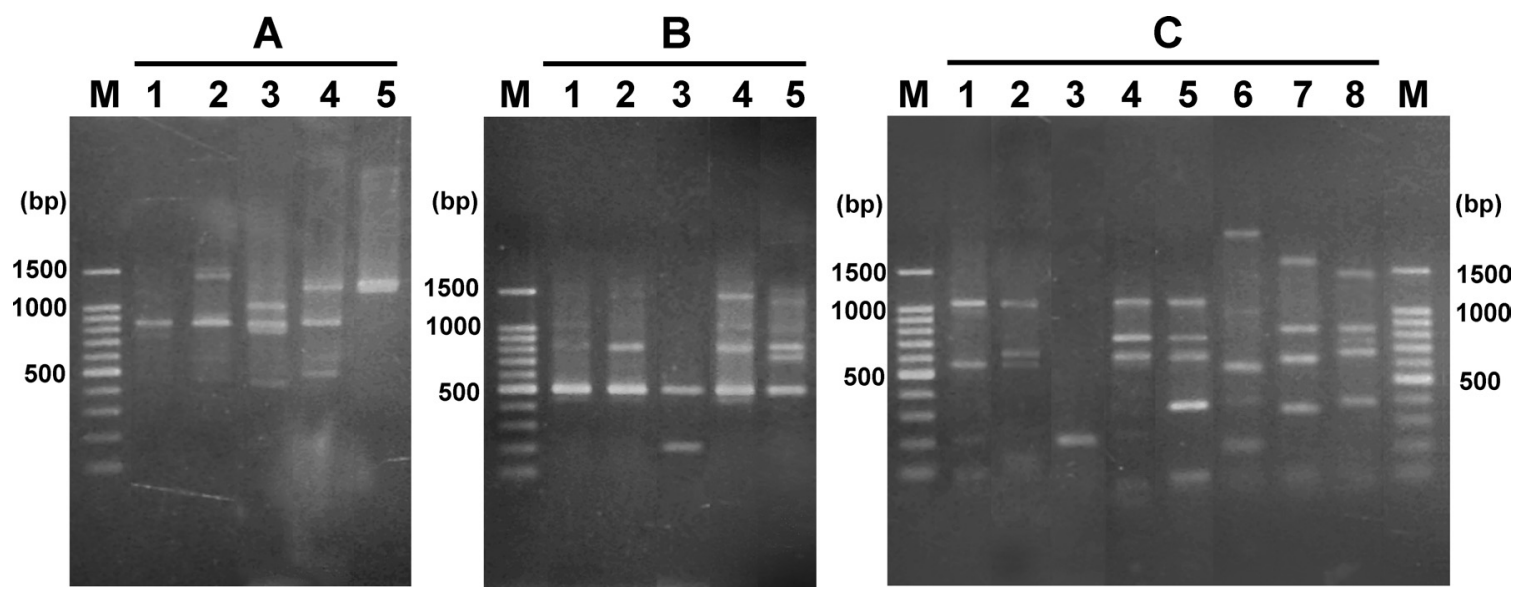

Fig. 2. RAPD patterns of DNA of wild C. formicarius amplified by the three primer sets. This study referred to RAPD patterns as A, B and C types by primer sets of T13/T13 (5'-AGGACTGCCA-3'), T05/T05 (5'-GGGTTTGGCA-3') and T01/T07 (5'GGGCCACTCA-3', 5'-GGCAGGCTGT-3'), respectively. Lanes 1 to 5 in A, 1 to 5 in B, and 1 to 8 in C represent RAPD patterns found in all weevils tested using three primer sets, $\mathrm{A}, \mathrm{B}$ and $\mathrm{C}$, respectively. Approximately $560 \mathrm{bp}$ in $\mathrm{C}_{1}$ and $\mathrm{C}_{2}, 650 \mathrm{bp}$ in $\mathrm{C}_{4}$ and $\mathrm{C}_{5}$, and $750 \mathrm{bp}$ in $\mathrm{C}_{5}$ were excluded due to a lack of reproducibility in this study. Lane $\mathrm{M}$ represents a 100-bp DNA ladder sizemarker.

$560 \mathrm{bp}$ in $\mathrm{C}_{1}$ and $\mathrm{C}_{2}, 650 \mathrm{bp}$ in $\mathrm{C}_{4}$ and $\mathrm{C}_{5}$, and $750 \mathrm{bp}$ in $\mathrm{C}_{5}$ ) were not reproducible, they were excluded from the detected RAPD patterns of type C.
Combining the three types of RAPD patterns of three types detected for each weevil resulted in 27 distinctive categories (Table 2). The number of 


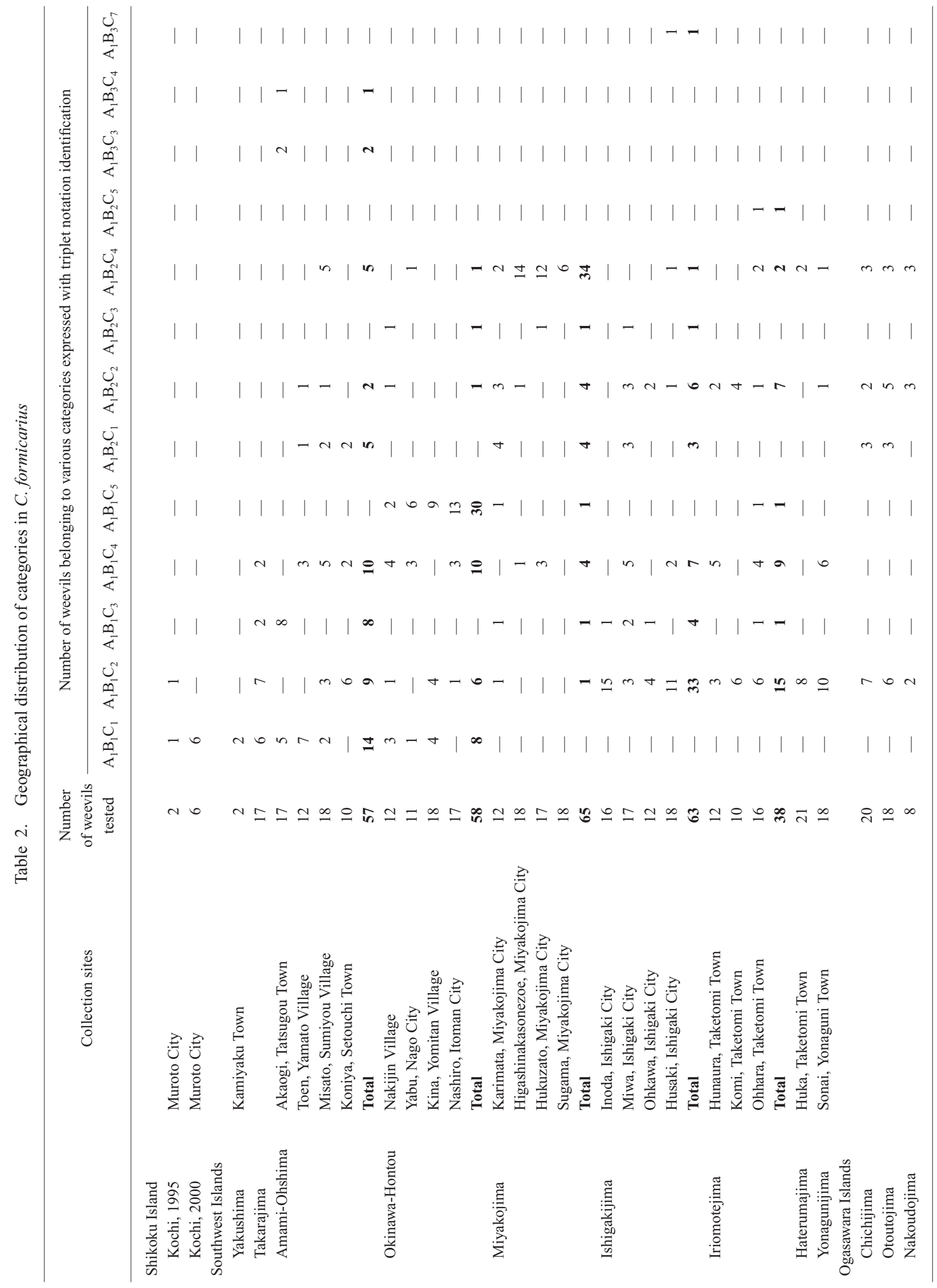




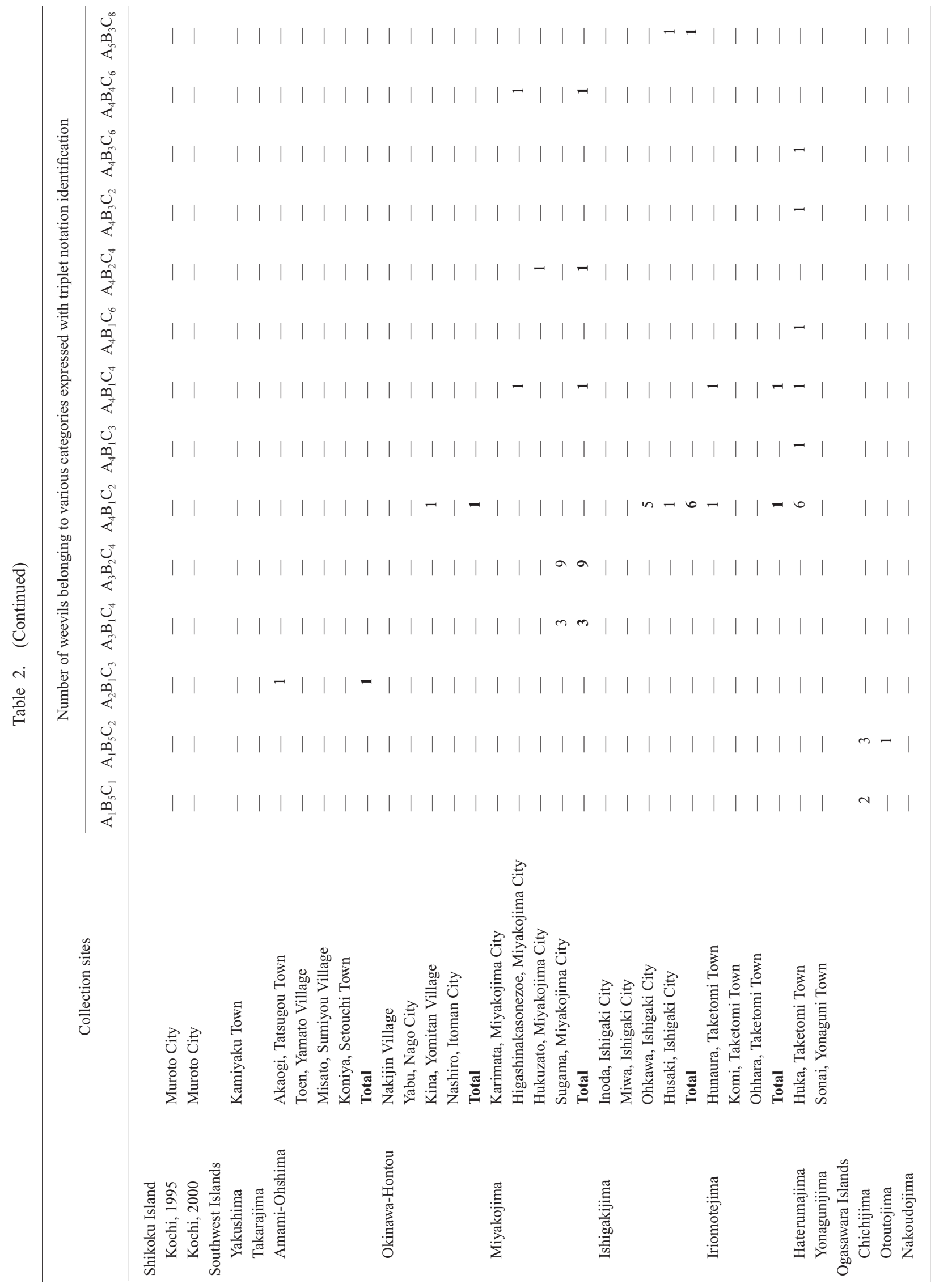


categories varied widely among islands. Some categories were found commonly on most islands, whereas several were found on only a few islands. This was also the case among different collection sites within the same island. It is notable that category $\mathrm{A}_{1} \mathrm{~B}_{1} \mathrm{C}_{1}$ was common only on Okinawa-Hontou Island and the more northern islands of the Southwest Islands, but was not present on other islands (Table 2). Individuals from Muroto City and Yakushima Island were classified into either $\mathrm{A}_{1} \mathrm{~B}_{1} \mathrm{C}_{1}$ or $\mathrm{A}_{1} \mathrm{~B}_{1} \mathrm{C}_{2}$ (Table 2).

Mendel et al. (1994) compared the RAPD patterns of Israeli pine bast scale, Matsucoccus josephi, individuals and estimated that its invasion pathway occurred from Israel to Cyprus. We used the RAPD pattern-based method proposed by Kawamura et al. (2002) to estimate the invasion sources of C. formicarius to two areas of Japan. If we assume that the sources of the weevils that invaded Muroto City and Yakushima Island were within Japan, the characteristic geographical distribution of $A_{1} B_{1} C_{1}$ described above suggests that the weevils collected on Yakushima Island originated from Okinawa-Hontou Island or the more northern islands of the Southwest Islands. For the Muroto invasion in 1995, we estimated that individuals categorized either as $A_{1} B_{1} C_{1}$ or $A_{1} B_{1} C_{2}$ were transported together from the same source as described above.

More reliable estimation methods of genetic distances such as those achieved through DNA sequencing are more expensive and time-consuming than RAPD-PCR (Unruh and Woolley, 1999). In plant quarantine projects, the estimation of the source of newly invaded pests requires the quick identification of many individual weevils. In such a case, RAPD-PCR is preferable, despite its limitations, because of its relatively low cost and time requirements, if the procedure and the interpretation of its results are preformed carefully.

The ability to make accurate identifications using markers increases with the number of diagnostic markers (Campton, 1987). Using the triplet notation identification method proposed by Kawamura et al. (2002), we showed that there were common triplet notation categories in the populations of Okinawa-Hontou Island and the northern islands and estimated the source of the recently invaded weevils in Muroto City and Yakushima Island. Hence, this triplet notation method is useful in classifying insect populations using RAPD markers. For a more precise estimation of weevil invasion sources using this method, it will be necessary to assess and classify in triplet notation the RAPD patterns of more weevils from both Japan and its neighboring countries.

\section{ACKNOWLEDGEMENTS}

We thank Messrs. H. Kamiwada (Kagoshima Agricultural Improvement and Advisory Center), S. Hayashikawa (Ohshima Branch, Kagoshima Prefectural Agricultural Experiment Station), H. Saragai (Naha Plant Quarantine Station), S. Sato (Ogasawara General Office), M. Takai and I. Yamashita (Kochi Prefectural Agricultural and Forestry Research Center) and S. Kawasaki (Kagoshima Prefectural Plant Protection Office) for providing specimens of $C$. formicarius. We also thank Drs. Y. Sakuratani, I. Kandori and T. Nonomura for their kind help. This study was partly supported by the Plant Protection of the Japan Ministry of Agriculture, Forestry and Fisheries, Grant-in-Aid for Special Scientific Research on Agriculture, Forestry and Fisheries.

\section{REFERENCES}

Black, W. C., IV (1993) PCR with arbitrary primers: approach with care. Insect Mol. Biol. 2: 1-6.

Callejas, C., A. Velasco, A. Gobbi, F. Beitia and M. D. Ochando (2005) Fast discrimination (RAPD-PCR) of the species forming the pest complex Aleurodicus dispersus-Lecanoideus floccissimus (Hom., Aleyrodidae). J. Appl. Entomol. 129: 382-385.

Campton, D. E. (1987) Natural hybridization and introgression in fishes: methods of detection and interpretation. In Population Genetics and Fishery Management (N. Ryman and F. Utter eds.). University of Washington Press, Seattle, Washington, pp. 161-192.

Caterino, M. S., S. Cho and F. A. H. Sperling (2000) The current stage of insect molecular systematics: a thriving tower of babel. Annu. Rev. Entomol. 45: 1-54.

Cognato, A. I., S. O. Rogers and S. A. Teale (1995) Species diagnosis and phylogeny of the Ips grandicollis group (Coleoptera: Scolytidae) using random amplified polymorphic DNA. Ann. Entomol. Soc. Am. 88: 397-405.

Fujimoto, K., T. Hirata and T. Matsuoka (2000) Recent emergent controls of sweet potato weevils (2) In Muroto, Kochi Prefecture. Plant Prot. 54: 453-454 (in Japanese).

Gawel, N. J. and A. C. Bartlett (1993) Characterization of differences between whiteflies using RAPD-PCR. Insect Mol. Biol. 2: 33-38.

Hiramatsu, M. (1996) Invasion of sweet potato weevil, Cylas formicarius (Fabricius) into Muroto-city in Kochi Pref., Japan. Koube Plant Prot. 916: 6 (in Japanese).

International Institute of Entomology (1993) Distribution Maps of Pests: Cylas formicarius (F.). Series A (Agricultural), Map Number 278. International Institute of Entomology, London.

Jansson, R. K., L. J. Mason and R. R. Heath (1991) Use of 
sex pheromone for monitoring and managing Cylas formicarius. In Sweet Potato Pest Management, A Global Perspective (R. K. Jansson and K. V. Raman eds.). Westview Press, Boulder, pp. 79-138.

Kambhampati, S., W. C. Black, IV and K. S. Rai (1992) Random amplified polymorphic DNA of mosquito species and populations (Diptera: Culicidae): techniques, statistical analysis, and applications. J. Med. Entomol. 29: 939-945.

Kawamura, K., T. Sugimoto, Y. Matsuda and H. Toyoda (2002) Detection of polymorphic patterns of genomic DNA amplified by RAPD-PCR in sweet potato weevils, Cylas formicarius (Fabricius) (Coleoptera: Brentidae). Appl. Entomol. Zool. 37: 645-648.

Maehara, S. (1998) Invasion of sweet potato weevil, Cylas formicarius (Fabricius) into Yakushima Island in Kagoshima Pref., Japan. Kyushu Plant Prot. 555: 2 (in Japanese).

Mendel, Z., D. Nestel and R. Gafny (1994) Examination of the origin of the Israeli population of Matsucoccus josephi (Homoptera: Matsucoccidae) using random amplified polymorphic DNA-polymerase chain reaction method. Ann. Entomol. Soc. Am. 87: 165-169.

Miyatake, T., S. Moriya, T. Kohama and Y. Shimoji (1997) Dispersal potential of male Cylas formicarius (Coleoptera: Brentidae) over land and water. Environ. Entomol. 26: 272-276.

Moriya, S. and S. Hiroyoshi (1998) Flight and locomotion activity of the sweetpotato weevil (Coleoptera: Brentidae) in relation to adult age, mating status and starvation. $J$. Econ. Entomol. 91: 439-443.

Moya, A., P. Guirao, D. Cifuentes, F. Beitia and J. L. Cenis (2001) Genetic diversity of Iberian populations of Bemisia tabaci (Hemiptera: Aleyrodidae) based on random amplified polymorphic DNA-polymerase chain reaction. Mol. Ecol. 10: 891-897.

Nawa, U. (1903) On the sweet potato weevil. Kontyu Sekai 7: 327-330 (in Japanese).
Nishioka, T., S. Kawasaki, S. Hiraoka, A. Kamifukumoto, H. Kuwahara, T. Ide, S. Sueyoshi and S. Ito (2000) Recent emergent controls of sweet potato weevils (1) In Kagoshima Prefecture. Plant Prot. 54: 448-452 (in Japanese).

Oogaki, H. and H. Yokoyama (2002) Eradication of sweet potato weevil, Cylas formicarius (Fabricius) in Murotocity in Kochi Pref., Japan. Koube Plant Prot. 951: 2 (in Japanese).

Sugimoto, T., Y. Sakuratani, O. Setokuchi, T. Kamikado, K. Kiritani and T. Okada (1994) Estimations of attractive area of pheromone traps and dispersal distance, of male adults of sweet potato weevil, Cylas formicarius (Fabricius) (Coleoptera; Curculionidae). Appl. Entomol. Zool. 29: 349-358.

Unruh, T. R. and J. B. Woolley (1999) Molecular methods in classical biological control. In Handbook of Biological Control: Principles and Applications (T. S. Bellows and T. W. Fisher eds.). Academic Press, San Diego, New York, pp. 57-85.

Wilkerson, R. C., T. J. Parsons, D. G. Albright, T. A. Klein and M. J. Braun (1993) Random amplified polymorphic DNA (RAPD) markers readily distinguish cryptic mosquito species (Diptera: Culicidae: Anopheles). Insect Mol. Biol. 1: 205-211.

Williams, C. L., S. L. Goldson, D. B. Baird and D. W. Bullock (1994) Geographical origin of an introduced insect pest, Listronotus bonariensis (Kuschel), determined by RAPD analysis. Heredity 72: 412-419.

Williams, J. G. K., A. R. Kubelik, K. J. Livak, J. A. Rafalski and S. V. Tingey (1990) DNA polymorphisms amplified by arbitrary primers are useful as genetic markers. $\mathrm{Nu}$ cleic Acids Res. 18: 6531-6535.

Wolfe, G. W. (1991) The origin and dispersal of the pest species of Cylas with a key to the pest species groups of the world. In Sweet Potato Pest Management, A Global Perspective (R. K. Jansson and K. V. Raman eds.). Westview Press, Boulder, pp. 13-43. 